\title{
Colaboratividad y solidaridad como regreso al mundo en la filosofía de Hajime Tanabe ${ }^{1}$
}

\section{Collaborativity and Solidarity as a Returning to the World in Hajime Tanabe's Philosophy}

\author{
Rebeca Maldonado \\ Universidad NaCional Autónoma de MÉxico
}

\section{Resumen:}

El presente texto explora en el pensamiento de Tanabe la colaboratividad y la solidaridad como dimensiones de la nada en tanto que éstas son posibles desde la perspectiva del no-ego (yo-vacío o sujeto vacío) o muerte continua del ego a lo cual llama metánoia y que como camino de pensamiento le llama metanoética. Para Tanabe la continuidad de la metánoia permite una forma de existencia histórica que hace posible otro modo de ser en el mundo, marcado por la solidaridad y la colaboratividad, también llamado "regreso al mundo" (gensō-ekō, en japonés). De este modo es desde la nada absoluta que se abre una especie de intersticio con otras sociedades y culturas.

Palabras clave: colaboratividad, solidaridad, la nada, no-ego, metánoia, regreso al mundo

\begin{abstract}
:
This paper explores Tanabe's thoughts on collaborativity and solidarity as dimensions of nothingness in so far as they are possible from the perspective of the non-self (empty-self or empty subject) or the continuous death of the self, which is called metanoia and, as a way of thinking, metanoetics. For Tanabe, the continuity of metanoia allows for a historical form of existence that makes possible another mode of being in the world indicated by solidarity and collaborativity, also known as

${ }^{1}$ El presente texto forma parte del proyecto "El pensamiento topológico en Japón. Un estudio de la concepción de la naturaleza, el espacio y el lugar en la filosofía, la religión y la estética japonesas" (MINECO-FFI12015-65662-P), de la Universidad Pompeu Fabra.
\end{abstract}


"returning to the world" (gensō, in Japanese). From the absolute nothingness, as a consequence, a kind of interstice with other societies and cultures opens up.

Keywords: collaborativity, solidarity, nothingness, non-self, metanoia, returning to the world

No es posible entender ni un poco Filosofía como metanoética sin el contexto que enmarca la obra. Según cuenta Hajime Tanabe, él comenzó a dictar una serie de conferencias en la Universidad de Kioto en octubre de 1944; esas conferencias son las que trabajadas con detenimiento compondrían esta obra magna de Tanabe y son, además, la última serie de conferencias que Tanabe daría en la Universidad de Kioto. Él impartió las conferencias en medio de circunstancias trágicas, en donde "los miedos y las ansiedades eran más fuertes cada día conforme la miseria y el desastre continuaban esparciéndose" a causa de la guerra. (Tanabe, 2014: 71). Señala que a pesar de la enfermedad logra terminar sus conferencias en diciembre de 1944. Tanabe se jubila de la Universidad de Kioto en febrero de 1945. Y, a finales de julio de 1945, se muda a una zona rural, logrando ordenar su obra en los siguientes dos meses. La guerra duró diez años y sólo tocó su final con las bombas de Hiroshima y Nagasaki, el 6 y 9 de agosto, pero sobre todo con el anuncio de la rendición incondicional de Japón por parte del emperador Hiroito el 15 de agosto de 1945. Las palabras del emperador dirigidas al pueblo japonés por medio de la radio son memorables:

Después de considerar profunda y detenidamente la situación mundial y la condición del imperio, con el deseo de aprovechar la coyuntura actual y tomando una medida de emergencia, declaro por este medio a todos vosotros mis fieles súbditos que: la situación bélica no es favorable, ni la coyuntura mundial nos resulta provechosa, lo que me ha llevado a ordenar al gobierno imperial que acceda las demandas del comunicado de los aliados y que siguiendo la marcha de los acontecimientos aceptéis lo insoportable y soportéis lo insufrible, hasta lograr inaugurar una gran paz para todas las edades. (Lozoya y Kerber Palma, 2011: 289)

Para Tanabe, como para todo el pueblo japonés, esto es la hecatombe, pero Filosofía como metanoética es la filosofía que desde meses atrás pensaba e intentaba nombrar esta catástrofe que en su interior se conforma una y otra vez por la conciencia autosustentada y autoafirmada: 
Entonces, Japón se encontró con el infeliz destino de una rendición incondicional, hundiéndose así la nación entera, incluyéndome yo en una profunda pena. Nosotros los japoneses tenemos que realizar la metanoésis cuando reflexionamos sobre cómo esta catástrofe ocurrió. Al mirar hacia atrás me doy cuenta que mi propia metanoésis del año anterior, estaba destinada para preparar el futuro de mi país. (Tanabe, 2014: 73)

Tanabe como lo señala en el Prefacio escrito en octubre de 1945, muestra arrepentimiento público por no haberse inmiscuido ni comprometido en los asuntos políticos del momento, por refugiarse en la filosofía como asunto exclusivamente teórico; por no haber manifestado abiertamente sus críticas al gobierno militar, pensando que, por otro lado, exponía a su país al enemigo. De esta manera Tanabe se ve forzado a pensar el arrepentimiento en japonés zange y proponer una lógica del arrepentimiento a la cual llama metanoética o también filosofía como camino del arrepentimiento. Tanabe en su obra piensa el arrepentimiento colectivo como la única vía de transformación y más aún, de salvación. En este sentido vemos que Tanabe con su obra ofrece en la teoría y en la práctica una disculpa.

Para Tanabe, el pecado y el mal no constituyen un accidente, es decir, lo que nos arroja a nuestra individualidad, autosustentación y autosuficiencia, desde la lógica de la identidad, no es algo individual, sino la determinación negativa de nuestro ser que "descansa en el fundamento de la existencia en general" (Tanabe, 2014: 80). Es aquí donde debemos comprender el significado del propio poder (jiriki) que en contraposición al Otro poder (tariki) lanza al individuo a una empresa de autosustentación y lo hace caer en lo que Tanabe llama orgullo y arrogancia (honganboroki), tendencia hacia el mal que nunca puede ser suprimida, es decir, el "mal radical" de la existencia humana. La fe en el Otro-poder "significa confesar la propia impotencia y, ser llevado al humilde reconocimiento de que uno no tiene nada en qué apoyarse, dejarse ir a uno mismo por completo" (2014). Tanabe en su impresionante obra, a través de las nociones fundamentales del budismo de la Tierra Pura o budismo Shin como tariki y jiriki, Otro poder y propio poder, habla de la transformación del propio poder en Otro Poder, de la cual depende el cambio radical de la existencia de un yo a un no-yo. Metanoesis consiste en arrepentimiento por los errores cometidos por no poder remediar las faltas. Metanoesis es transformación del propio poder en Otro poder, transformación de jiriki en tariki: "Sólo cuando nos abandonamos a nosotros mismos y confiamos nuestro ser a la gracia del Otro Poder (tariki), nuestra existencia podrá acceder a la verdadera libertad" (2014).

En este texto quiero presentar el ensayo de despertar social que encierra la metanoética de Hajime Tanabe y que determina el lugar como «regreso al mundo». 
Para Hajime Tanabe, la tarea de salvar a todos los seres sintientes propia del budismo Mahayana, se vuelve más apremiante y acuciante en el budismo verdadero de la Tierra Pura que, también perteneciente al Mahayana, establece la senda de no solo ir a la Tierra Pura $(\bar{o} s \bar{o})$ sino regresar al mundo para salvar a los seres sintientes del sufrimiento $($ gensō $) .{ }^{2}$ El fundador de este budismo fue Shinran, reformador del budismo en la Era Kamakura. Podríamos decir que Tanabe con su obra Filosofía como metanoética lleva la tarea del budismo de la Tierra Pura a su culminación, al pensar la transformación, el renacimiento social y la renovación.

\section{Metanoesis o metánoia}

Metanoesis o metánoia, en el contexto de la obra de Tanabe, es práctica continua de desplazamiento del yo, práctica de anulación y autonegación; solo bajo esa condición el yo como ser vacío se transforma en eje de transformación que le permitirá ser mediador entre yo y otro, de la misma manera en que también permite el gozne relacional entre el yo y el otro, entre unos y otros. Individuos autocentrados, enclaustrados, incapaces de desplazarse a sí, son incapaces de ser mediadores o de servir de "entre" entre el yo y el otro, el ser para Tanabe es ser upāya (medio). ${ }^{3}$ Esto permite ver que la nada (como fuerza desustancializadora) se erige en Hajime Tanabe como lo absoluto y es esa nada testificada en el trabajo de abandono y desistimiento, a través del trabajo de zange (vergüenza y arrepentimiento), la que lleva a romperse al yo en la arena de las contradicciones, para convertirlo en ser vacío o no-yo $(m u g a) .{ }^{4}$

${ }^{2}$ Osō y gensō son dos conceptos centrales que Tanabe recupera del budismo de la Tierra Pura de Shinran; osō significa ir hacia la Tierra Pura y, gensō, regreso al mundo desde la Tierra pura para salvar a todos los seres sintientes (Tanabe, 2014: 79).

${ }^{3}$ Upayya en la literatura budista es medio de liberación de uno mismo y de los demás, tiene que ver con las virtudes perfectas en el sentido de que el bodisattva es aquel que cuenta con esos medios o habilidades para salvar a los demás: palabras, discursos, acciones, incluso la facultad de "aparecer en destinos nefastos como los infiernos para rescatar a los seres que allí habitan” (Arnau, 2006). La radicalidad de Tanabe se encuentra en mostrar que la verdad es ser upãya, yo me he atrevido a extender este término y pensarlo en cercanía con la noción de Entre (Zswichen) como el centro apertor de la cuaternidad, apertor de relaciones en el Heidegger de Aportes a la filosofía.

${ }^{4}$ Filosofía como metanoética, escrita entre 1944 y 1945, surge del contexto crítico de la Segunda Guerra mundial y el papel que jugó el militarismo japonés en ella, desde 1934. Tanabe como filósofo a través de su obra anterior Lógica de las especies justificó el lugar dependiente del individuo del Estado y, en la práctica, azuzó a jóvenes estudiantes a partir a la Guerra para defender a la nación japonesa, sin embargo, en medio del estrepitoso fracaso y la muerte, Tanabe experimenta vergüenza y arrepentimiento (zange). John W. Dower escribe Embracing Defeat para tratar los múltiples aspectos que comprenden la derrota japonesa, sin olvidar hacer un comentario a la obra de Tanabe en el apartado "Buddhism as 
Cualquier movimiento de autosustentación se revela como una ilusión. En este sentido metanoesis produce un giro en la razón basada en la autonomía hacia un sujeto vacío relacional en múltiples dimensiones o que siempre en el medio inestable y no fijo abre a la relación entre yo y otro, lo uno y lo otro, vida y muerte, afirmación y negación, ir a la Tierra Pura y regresar al mundo desde la Tierra Pura. Es ese ser

Repentance and Repentance as Nationalism”. Se recomienda la revisión de este texto porque está escrito por un historiador completamente desprevenido del trasfondo filosófico y ontológico del pensamiento de Tanabe, buscando hacer presente su propuesta de que en dicha obra existe todavía el nacionalismo y no un arrepentimiento. Visto todo completamente desde fuera de la filosofía, nos señala que la idea del arrepentimiento colectivo proviene del primer ministro Higashikuni quien al explicar las diferentes causas de la derrota del Japón incluye leyes restrictivas, errores por parte de autoridades y militares y una moral popular pobre, al participar en el mercado negro entre otras cosas, por lo cual declara: "el ejército, oficiales civiles y el pueblo como un todo debe completamente autoreflexionar y arrepentirse. Yo creo que el arrepentimiento colectivo de cientos de millones es el primer paso en la resurrección de nuestro país, el primer paso para lograr la unidad de nuestro país" (Citado por Dower, 1999: 496). Dower además señala la aguda respuesta de un campesino escrita en un periódico: "Esta guerra comenzó sin saber nada los campesinos al respecto [...]. No hay necesidad de arrepentimiento por algo que nosotros no hicimos. Arrepentimiento es necesario para aquellos que traicionaron y engańaron a la gente" (1999). Dower considera que el arrepentimiento de Tanabe, a diferencia del de Higashikuni, es muy densamente argumentado, pues proviene de la filosofía. Pero en opinión de Dower el arrepentimiento de Tanabe es nacionalista, ya que al proponer que el arrepentimiento debe practicarse por todas las naciones y culturas, lo hace desde la "sabiduría ancestral del Japón", es decir desde Shinran, fundador del Budismo Verdadero de la Tierra Pura. Esta crítica desde la perspectiva del siglo XXI multicultural e intercultural del no se sostiene. Hoy aceptamos que las filosofías hablen desde y de su propia tradición y aceptamos que el conocimiento filosófico tiene muchas matrices; aceptamos la existencia de una filosofía mesoamericana, una filosofía china, una filosofía árabe, etcétera. La crítica de Dower no llega a ser consistente con la apertura a las filosofías no occidentales que ha acontecido en el pensamiento filosófico, y de lo cual uno de sus principales Escuelas en este sentido es la Escuela de Kioto. Tanabe logra pensar la idea del arrepentimiento en el contexto de Shinran y el lugar fundamental que tiene como fuerza transformadora del autocentramiento. Por otro lado, la crítica demasiado externa a la filosofía de Tanabe por parte de Dower, resulta infértil a la hora de calibrar las dimensiones del arrepentimiento en términos filosóficos en la obra de Tanabe. Prueba de ello es que Dower no logra interpretar la necesaria crítica a la filosofía occidental que Tanabe aporta a la filosofía y su importancia en el contexto contemporáneo, a causa de querer ver en la crítica a la filosofía occidental un signo del nacionalismo. Esto puede verse en afirmaciones como: "El reclamó estar iluminando un camino japonés singular para la redención, una sabiduría trascendente más grande que cualquier pensamiento occidental producido" (1999). Dower no está capacitado para entender la confrontación que Tanabe realiza con Heidegger, Nietzsche, Schelling, Pascal, Eckhart, en cada uno de los respectos que él quisiera resaltar, y por lo mismo, es incapaz de señalar en qué radica la riqueza de la propuesta de Tanabe que es lo que nosotros en este trabajo queremos señalar que es el principio del beneficio de otro qua beneficio propio. En la actualidad, la filosofía japonesa de la Escuela de Kioto es conocida por sus aportaciones a la crítica de la subjetividad y su aportación para el punto de vista de no-ego o la visión del sujeto vacío. Finalmente, es necesario señalar que no solo Tanabe ha hecho filosofía del arrepentimiento y la vergüenza, tenemos la obra de Paul Ricoeur llamada Finitud y culpabilidad así como la de Vladimir Janklevitch La mala conciencia. Ricoeur analiza la experiencia de la caída y de la mancha y Jankelevitch el ciclo de la culpabilidad a la resurrección, muy en cercanía a Hajime Tanabe. 
vacío que al mismo tiempo, media la gran muerte y la gran resurrección, el ir hacia la Tierra Pura y regresar al mundo desde la Tierra Pura, ascenso y descenso, que instaura una dinámica doble en lo real en la que finalmente nuestra salvación es la salvación de los demás. ${ }^{5}$ Lo cual como estructura íntima de lo real revela el inútil esfuerzo de mirar por sí mismo y sus cosas, revela el inútil esfuerzo de atender los propios asuntos, que es lo que ha creado a las sociedades contemporáneas desde el punto de vista del sujeto moderno autónomo y autosuficiente. ${ }^{6}$

Cuando los seres despiertan a su rol mediador como seres vacíos, se alcanza el punto de vista de la reciprocidad y la mutualidad absoluta. Donde las cosas se encuentran en una unidad dinámica y móvil del tipo ni lo uno ni lo otro, ni uno ni dos, ni identidad ni diferencia.

\section{De la metanoesis al amor}

El ser vacío, en su continuo desplazamiento, inaugura la circularidad entre lo absoluto y lo relativo es decir, crea un movimiento continuo de conversión de jiriki (propio poder) en Tariki (otro poder) y de otro poder (Tariki) en propio poder (jiriki). ${ }^{7}$ Inaugura una oscilación permanente, un contrapunteo, un ascender qua

\footnotetext{
${ }^{5}$ En este sentido vale la pena recuperar lo dicho por Nobuo Kazashi: "Actualmente la palabra 'zange' [vergüenza y arrepentimiento] puede sonar muy anticuada como para ser aplicada a la vida social, o por lo menos, completamente obsoleta. Sin embargo, su doble significado de 'arrepentimiento' y 'crítica al logocentrismo' traídos a la luz por Tanabe a través del uso de metanoética, tiene una importancia relevante. Especialmente, después del desastre nuclear de Fukushima en marzo de 2011 nosotros estamos siendo forzados a considerar con un sentimiento de gran tristeza y piedad propia del arrepentimiento el camino que ha tomado la civilización humana desde su fundamento"(Kazashi, 2017: 108).

${ }^{6}$ Dice Nobuo Kazashi: "In other words, a new 'subject of philosophy' can begin to be at the very limit where the ordinary 'subject' is abandoned and dismantled” (Kazashi, 2017: 108). En este mismo sentido señala Johannes Laube que Filsofía como metanoética es una aproximación a la filosofía por la vía de la autoconciencia de la experiencia ética, y no es basada en la autonomía de la razón (Laube, 1990: 317). Nobuo Kazashi pone el acento para proponer el abandono de la razón autónoma en la metanoesis, Laube en el Otro poder, ambas se complementan, pues Tariki ha de entenderse como esa fuerza desustancializadora de toda identidad y sustancialidad. En este sentido el abandono de sí es justo acción de Tariki.

${ }^{7}$ Jiriki y Tariki, propio poder y Otro poder; en inglés la traducción respectiva de estos conceptos es self-power y Other Power. Ambos son conceptos centrales de Shinran, reformador religioso del siglo XII y creador del Budismo verdadero de la Tierra Pura en el siglo XII en Japón. Para Shinran jiriki es orgullo por nuestros propios actos, la confianza en nuestros propios méritos, el "esfuerzo para el logro del nacimiento" (Bloom, 2007: 87). Mientras que Otro poder es como señala Shinran "ser libre de toda forma de cálculo" (2007). O bien: "Lo que nosotros llamamos Otro Poder es que en él no hay lugar para la más mínima partícula de cálculo por parte del practicante. Por esta razón debe decirse: la no obra es verdadera obra" (2007).-
} 
descender, un yo qua otro, un continuo mecimiento e inquietud, pero lo que está moviendo permanentemente es metanoesis, que es una nada viva. Desde esta perspectiva lo que media a la (otra) historia, no es la materia, ni el espíritu, ni las cosas ni la mente, sino el "ser vacío" (Tanabe, 2014: 369). La mente y las cosas están mediadas por la realidad de la nada absoluta (ser vacío), que es existencia material y sentido espiritual, ambos mutuamente dependientes y por eso independientes, independientes y por eso dependientes.

Así otra dimensión se encuentra entre el hedonismo y el moralismo, ya que el placer se transforma en tedio, y el moralismo carente de plenitud, se vuelve en contra de nuestra naturaleza humana; sólo el amor reúne a ambos entendido como "gozo de una unidad transindividual de reconciliación e instrucción mutuas, trabajando al interior de una comunidad humana de individuos que median individuos" (Tanabe, 2014: 370-371). Para Tanabe la sociedad del regreso al mundo une moralismo y hedonismo a través del amor basado en la instrucción y en la reconciliación. Dice Tanabe:

Todo esto nos lleva a ver que un principio adecuado y positivo de la existencia humana no puede estar sustentado en un punto de vista individualista, sino en la dicha y la plenitud del amor en la existencia social humana. El amor es una relación concreta de mediación transformadora en donde la autonegación se convierte en autoafirmación. En verdad, (...), el amor es la nada y, al mismo tiempo, la nada es amor. En la negatividad de la Gran Negación, el amor tiene algo en común con la austeridad moralista; y, en la plenitud y la dicha de la Gran Compasión, también puede participar del goce estético de la cultura. El amor sintetiza ambos aspectos del sí mismo y transforma a la negación en un mediador de la afirmación (...) Aquí es donde se encuentra el objetivo del ser humano como ser social. (Tanabe, 2014: 371)

De manera que el despertar a la vida después de haber muerto, o despertar en el morir y transformarse en ser vacío, que es el trabajo de la metanoesis tanabiana, da lugar al amor como un cooperar con lo absoluto para salvar a otros seres relativos, es decir, la metanoesis da lugar al Amor como Gran Compasión.

\section{El amor}

Tanabe piensa que el amor en diferentes formas está presente en la historia de la filosofía occidental; así se da cuenta que Platón considera que "cada individuo debería hacer una contribución al Estado de acuerdo a su posición dentro del 
mismo" (Tanabe, 2014: 372). Se da cuenta que Aristóteles propone a "la amistad como un principio de las relaciones humanas que existe de manera independiente de las virtudes individuales" y que "realiza una función integradora en el Estado que la justicia no puede realizar" (Tanabe, 2014). Con lo cual Aristóteles propone "un principio de la realidad social für sich diferente del principio de la existencia individual” (Tanabe, 2014). Por su parte, Agustín pensó que el sentido de la historia era el establecimiento de la ciudad de Dios en la Tierra, "una ciudad en la cual el amor fuera la coexistencia pacífica de aquellos justificados por la gracia de Dios" (Tanabe, 2014).

Así que ya sea que el amor se piense como algo que trasciende al individuo o que media la existencia social, o que permite crear una contribución al Estado, el amor es relación, vínculo y coexistencia. Mas no solo en la historia del pensamiento el amor es principio social, también en el cristianismo con su propuesta de amor al prójimo. Nos dice Tanabe: "Si el amor de Dios no estuviera mediado por el amor al prójimo, y si no fuese actualizado en las relaciones interhumanas, la existencia de Dios no podría ser testimoniada en la tierra. En este sentido puede decirse que el cristianismo es social por naturaleza" (Tanabe, 2014: 372). Tanabe parece encontrar en el cristianismo y la historia del pensamiento occidental algo que también él mismo andaba buscando: un principio de cohesión, de cooperación, de encuentro, de unidad y lo encuentra en San Agustín. Con respecto al cristianismo, el budismo antiguo, diferente al budismo Mahayana, le parece una escapatoria del mundo del samsara, mientras que el evangelio del amor cristiano tiene un sentido social. Por lo que no es el budismo antiguo lo que servirá de guía histórica a Tanabe, sino el budismo Mahayana, a través del modelo aportado específicamente por el bodisattva Dharmākara.

Se cuenta en el Sutra Mayor que Dharmākara se presentó ante el buda Lokesvarāja y expresó en versos su aspiración original, su resolución: "Yo resuelvo convertirme en un Buda / igual en logro que tú, / Para liberar a los seres vivientes del nacimiento y muerte / y conducirlos al despertar" (The Larger Sutra, 2003: 267b). Esta aspiración original busca el despertar de todos los seres en todas las tierras búdicas.

Tanabe sin obviar el conflicto en la ciudad terrena, considera que el conflicto entre lo relativo y lo absoluto ha de pensarse dentro de la mediación y la transformación mutua del propio poder (jiriki) y el otro poder (tariki), para así poder entender de manera más creativa a la sociedad y al sí mismo en una relación donde la transformación es siempre mutua.

Sin lugar a dudas, Nishida en su Lógica del lugar y la cosmovisión religiosa desarrolla el concepto de compasión como el punto de vista que es capaz de abrazar lo 
que se nos opone y señala que el amor es la perspectiva sin la cual no se puede alcanzar la creatividad, que él trata de explicar con su concepto de acción intuición. Para Tanabe no es el punto de vista de la compasión entendido como abrazar lo que se nos opone, como el locus del yo y el otro, sino el punto de vista concreto alcanzado por el bodisattva que es necesario traer a cuento y explicitar. En el budismo Mahayana el ideal del bodisattva alcanza su máxima expresión en el budismo de la Tierra pura o budismo Shin. El budismo al transitar desde el punto de vista de la iluminación solitaria a "un acercamiento comunitario de acuerdo con el cual el dharma se transmite de maestro a discípulo" (The Larger Sutra, 2003: 377) ofrece el ideal del bodisattva. Debemos entender por bodisattva persona que a pesar de haber despertado deniega y pospone su entrada en el nirvana hasta que todos los seres alcancen el despertar, en este sentido la realización de una sociedad despierta es un imperativo implícito del Mahayana. Así que como piensa Tanabe el budismo Mahayana desarrolló el ideal de "beneficiarse a sí mismo-qua-beneficiar a los otros" (2003). Este principio es la verdad esencial del muga o no-yo "que [señala que] no hay sí mismo ni ego en la totalidad de la realidad -y que es el principio de la nada absoluta” (2003). ¿Cómo se piensa la actividad mediadora de la metanoética en el caso del ideal de bodisattva? El ideal bodhisáttvico indicaría que no existe un bien propio sin el beneficio de los otros o, mejor dicho, que el único bien propio es el beneficio de los otros, y esto es permitido por el no-yo o ser vacío. Por lo cual estamos de acuerdo en que no se trata de utilizar el bien ajeno como el logro de nuestro bien, o como un medio para lograr nuestro bienestar, sino la comprensión de que no hay dualidad entre yo y otros, por lo que el único bien propio es el beneficio de los demás. ${ }^{8}$

Para Tanabe, zange o el arrepentimiento y la vergüenza por nuestro afán de autosustentación en la era actual puede conducirnos a hacernos cargo del mal y de la caída, lo cual no encuentra ni en Bergson ni en Hegel. Esta Gran Negación es la que atestigua la Gran Compasión de la afirmación y la resurrección. Desde el interior de este atestiguamiento, la metanoética emerge como la transformación

${ }^{8}$ Cuando Johannes Laube trata de dilucidar el principio bodisattvico de beneficiarse a sí mismoqua-beneficio de otros, cae en otra dualidad: pensar que los méritos son transferidos a los otros y no la experiencia de la absoluta no dualidad entre yo y otros, de la que se desprendería la radicalidad de la idea de que el único beneficio es el beneficio de otros y eso es mi propio beneficio (Laube, 1990: 327). Esto me parece el ideal del bodisattva que enseńa el camino del gensō. Johannes Laube olvida que la transferencia de méritos todavía es un camino de propio poder. Además, creo que cuando él habla de gensō, no piensa en regreso al mundo, sino piensa en evangelizar: "What traditional, historical buddhismincluding the Buddhism of Shinran -has lacked heretofore is the element of the social an und für sich as universal law that applies to societies throughout the world" (1990). En realidad parece ser que él busca en el texto tanabiano la justificación de la cristianización. 
absoluta de la Gran Negación-qua-Gran Compasión (Tanabe, 2014: 378). La metanoética ha de tener el testimonio y la garantía de la Gran Compasión. Por esta razón, sólo en este proceso donde el yo se afirma como ser vacío y no puede intuirse como ser autoidéntico o como conciencia de una realidad autoidéntica, su extinción es al mismo tiempo testimonio de la gran compasión. "Aunque es nada es ser y aunque sea ser, oscila en la nada; como una estrella centelleante, su extinción es su aparición; y su aparición, su extinción" (2014). Todo lo que existe directamente es ser. Si la nada existiera previamente sería ser. No se obtendría de la negación. No se obtendría de manera mediada. Esa nada sería ser y no nada. La metanoética no es algo intuible; más bien:

[E]s traída a fe-iluminación a través de la acción. Solo una fe-iluminación, donde la transformación negativa actúa [...] puede realizar el autodespertar de la nada. En la medida en que la nada es fundamento trascendente de la acción-fe, se convierte en autodespertar de acuerdo al atestiguamiento donde el yo inmanente se niega y es transformado. (Tanabe, 2014: 379)

Y si solo por el despertar de la nada se atestigua la realidad del amor y se realiza la acción fe de la Gran compasión, si la nada es-qua-amor, entonces Buda Sakyamuni o Dharmākara son los ejemplos de que lo absoluto es el despertar y el despertar es el amor, pues es eso lo que les permite ser mediadores del absoluto. Si la realidad absoluta es el amor como no-ego o muga y si el no ego se realiza como amor, esta "Gran Negación como Gran Compasión” enseña que "el centro de la metanoética es la filosofía de tariki (otro poder)” (Tanabe, 2014: 80). Más allá del yo y de los otros, beneficiarse a sí como beneficiar a los demás es la mostración del despertar del absoluto. Tariki (otro poder) se realiza eternamente como regreso al mundo y salvación de los demás, por el bien del otro-qua-mi propio bien, el gensō absoluto es la vida en la salvación de los demás, solo esa vida es mediadora del absoluto, no aquella que permanece pacíficamente en la cima de la montańa, o en la quietud del hogar. Sakyamuni (también llamado el Tathāgatha, El así llegado) y Dharmākara, se dieron cuenta de que el despertar es el despertar de los otros y regresaron al mundo.

\section{El amor como mediación entre los relativos y el absoluto}

¿Cómo puede suceder que en la estructura del Tathāgatha bodisattva éste no pueda permanecer anidado en su propio poder, ni en la plenitud del samadhi, ni en la 
serenidad de su hogar, sino que tenga que regresar al mundo a salvar a todos los seres sintientes? ¿Será que la existencia en el amor como entrega a los otros es la única posible existencia en plenitud? Tariki (Otro poder mediador de los relativos) es la estructura toda de la realidad, el bodisattva no está dispensado de entregarse a sí tras su autoabandono a los seres relativos para salvarlos e instruirlos en la disciplina del autoabandono y la renuncia. Asimismo, el ser relativo tras su abandono del propio poder, por la mediación de Tariki, la absoluta nada, crea espacio para su negatividad y comprende que los seres relativos solamente como seres vacío son mediadores de Tariki, comprende que "la salvación no puede acontecer sin Tariki" (Tanabe, 2014: 382). La "salvación por Tariki" presupone "el poder de lo absoluto quien es 'otro"' (2014). La salvación por Tariki conduce a la entrega, a el ofrecimiento de todo cuanto pueda ser llamado mío, y en ese absoluto no tener, inicia la actividad mediadora, el sí mismo entonces descubre el ser mediador que es. Esta actividad mediadora de Tariki, nos hace entregarnos a los seres relativos, para realizar la mediación. En esta entrega a los otros, nos damos cuenta que "el absoluto no es el ser sino la nada" (2014). Esta es la relación más fundamental tras la destrucción de un yo basado en su autocentramiento y que, tras su descentramiento, permite la relacionalidad y mutualidad.

\section{Beneficiarse a sí como beneficiar a los demás como dictum del despertar se encarna en la vida activa del amor y la enseñanza: La figura del bodisattva}

Para pensar el modelo bodhisáttvico Tanabe se apoya en la figura de Dharmākara, pero no duda que en otras sociedades específicas Jesús es un bodhisattva mediador entre lo universal y lo específico. En el caso del Budismo de la Tierra Pura, Amida realiza su gensō absoluto como Dharmākara, Tanabe señala que Dharmākara

\footnotetext{
encarna la forma de los más avanzados, y así, sus acciones proporcionan un modelo de acción que los seres sintientes deben seguir para ser salvados (...) A todos los seres sintientes que entren en el camino de la salvación se les promete la budeidad (...) siempre y cuando sigan la disciplina de Dharmākara como su guía (...) a través de la negación absoluta. (Tanabe, 2014: 381)
}

Dharmākara funciona como símbolo del gensō absoluto, pues proporciona un modelo de acción y disciplina, que al imitarse deviene en guía para la salvación de otros seres relativos, que a su vez se transforman en actividad mediadora de 
transformación de otros seres relativos; así un gensō cada vez más amplio va transformando las sociedades específicas. ${ }^{9}$ Es así que encontramos la emergencia de la visión religiosa de la sociedad de Tanabe. Se trata de una sociedad donde tras el abandono de jiriki (propio poder), y tras convertirse en espacio para la espontaneidad de lo absoluto (nada absoluta), en su trabajo de salvación de todos los seres, el ser relativo también trabaja desde su autonegación en la salvación de los seres relativos que se encuentran en oposición en cuanto seres relativos, siguiendo el modelo del bodisattva. El gensō de lo absoluto (bodisattva Dharmākara, o también Sakyamuni), es la base del gensō relativo (es decir, la mediación entre los relativos y su enseñanza).

Para Tanabe la nada absoluta actúa de dos maneras, como acción y disciplina de Dharmākara y también actúa como confrontación entre un relativo y otro al interior de "lo específico" (Tanabe, 2014: 383). En el planteamiento de Tanabe, la nada absoluta aparece en la oposición mutua de los relativos y como transformación de lo relativo en muga o no ego en tanto conversión de jiriki en tariki. Y solo como transformación de jiriki en tariki, deviene mediador de la nada absoluta o en modelo que guía a los menos avanzados y contribuye en la creación de una sociedad de solidaridad que colabora en el trabajo de la salvación mutua, transformando finalmente confrontación mutua en ayuda mutua. Tanabe piensa en la creación de una sociedad donde los más avanzados guíen a los menos avanzados por la mediación del ideal del bodisattva, una sociedad donde a su vez los seres relativos devenidos en no yo, trabajen en la salvación de los otros y ayuden a los menos avanzados. ${ }^{10}$

9 “para mediar la relación de gensō entre los seres relativos, el gensō absoluto de lo absoluto devela su significado, a saber, que para el logro de la salvación de los seres relativos en su camino de ōsō, lo absoluto les proporciona un modelo de acción en la forma de la disciplina y acción de Dharmākara, símbolo del gensō absoluto. Y, al mismo tiempo, la acción misma de lo relativo, emprendida en imitación de lo absoluto y bajo su guía, deviene mediadora de la acción realizada por lo absoluto para la salvación de los otros seres relativos" (Tanabe, 2014: 383).

10 "La relación entre los seres relativos, objeto de la salvación, y los seres relativos, que colaboran en la obra de la salvación, está mediada por el gensō de los más avanzados. Ellos proveen de guía e instrucción a los menos avanzados, para que, después de haber sido salvados en su camino de ōsō, puedan a su vez tomar el camino de gensō y guiar e instruir también a los menos avanzados" (Tanabe, 2014: 384). 


\section{Bodisattva y lo específico}

Cuando Tanabe piensa las relaciones entre el Estado y la religión piensa que también el budismo verdadero de la Tierra Pura o budismo Shin puede ayudarnos a comprender la existencia social. En Nishida que pensaba que la existencia social consistía en esencia en transitar de lo creado a lo creador, dicha concepción no permite ver el conflicto y las crisis de la existencia social como tampoco "la conciencia de las realidades que llaman a las responsabilidades políticas y éticas del individuo" (Tanabe, 2014: 390). La religión no es el opio del pueblo, siempre y cuando se piense que además de ofrecer tranquilidad del alma inspire a la acción, es decir, la religión no puede ser un dormitivo. En suma, dice Tanabe: "El propósito de la vida humana no es el gozo de la cultura, sino el gozo de la armonía social" (2014).

Para Tanabe la sociedad específica y el individuo no se oponen necesariamente, pues en la mediación negativa entre la totalidad y el individuo ambos pueden coexistir armoniosamente. Y al mismo tiempo, la coexistencia posible entre el universal y el individuo es el mundo del medio hábil religioso. "Cuando el absoluto recibe y salva a los seres relativos a través del gensō absoluto, debido a su estructura, el Otro poder absoluto es necesariamente mediado por el propio-poder" (Tanabe, 2014: 393). La espontaneidad de los seres sintientes funge como capacidad mediadora del absoluto que los transforma en función mediadora para trabajar en la mutua mediación de los relativos. Solo así lo absoluto da lugar a que lo relativo sea relativo y da testimonio de su actividad mediadora. Por lo cual el absoluto que obra mediadoramente, no es objeto de contemplación sino "centro para la acción" (2014). La acción requiere del individuo como manifestación de la nada y del sustrato común que es la cultura. Esto abre dos posibilidades indispensables entre sí: 1) como mediadores de la nada absoluta y como manifestación de la misma, los seres sintientes avanzados como representantes de lo absoluto, pueden instruir a los menos avanzados y recibir instrucciones, según los conceptos y los términos de una doctrina en común, que da lugar a la sociedad específica, proporcionando una base en común de mediación. Por este camino surge un segundo aspecto, y esto es lo novedoso; 2) que en la medida que las sociedades mismas se transformen en sujetos de la nada y cada una sea mediadora de la salvación de las otras sociedades, las sociedades podrán comunicarse y hacer posible la comunidad, sin encontrarse limitadas por particularidad alguna. A esto Tanabe llamará la unidad de lo absoluto o lo general. Este es el punto en que los individuos mediadores "pueden alcanzar el amor mutuo y la simpatía que abarca la profundidad de la humanidad" (2014). Así los individuos se "abren a la influencia de una comunidad 
más penetrante" (2014). El individuo al ser mediado por la nada, está mediado por la libertad, lo que lo vuelve un ser permeable mostrando que "las culturas se comunican entre sí en el nivel profundo de la nada”. ${ }^{11}$

Para Tanabe pueden surgir individuos que atraviesen el patrón general y escapen de la mediación de lo específico "para comunicarse con el fundamento universal de lo humano", pero incluso en estos casos se encuentra "el trabajo mediador de lo específico" (Tanabe, 2014: 395). Jesús surge en un contexto particular, Buda Sakyamuni también. Tenemos entonces que los bodisattvas aparecen, de acuerdo con la situación particular y la especificidad de las sociedades: así las sociedades específicas, con sus problemáticas específicas, son medio hábil para la salvación de la sociedad. Los contextos específicos son importantes para la acción bodisáttvica, por lo que la salvación del individuo ha de encontrarse mediada por la particularización que propicia la sociedad específica. El nacionalismo, no es el nacionalismo de los Estados, sino la particularización de "la acción mediada por la nada absoluta" (2014) que es la que realiza el bodisattva, propiciando una permeabilidad con el fundamento humano universal desde el nivel profundo de la nada. Por lo cual si la nada es algo es libertad.

El budismo Shin en Japón, en su camino de gensō interpreta lo específico como mediador de la salvación, pues la comunidad específica como un upāya media la guía de la acción ejemplar del gensō. El budismo shin no solo introdujo la idea de una sociedad de la salvación, sino que además introdujo la idea de la estructura específica de esa sociedad. La especificación es cada una de las "formas que asume el Buda dependiendo de los diferentes tipos de seres sintientes y eso corresponde a la noción de sustrato específico" (2014). Tanabe se vale para afirmar esto de Kant, en él, el juicio teleológico se especifica a sí mismo dependiendo de los contextos.

11 "En la medida que las sociedades específicas puedan ser transformadas al grado de convertirse en sujetos de la nada y en mediadoras de la salvación, podrán comunicarse y hallar comunidad en su mediación de la nada, aun cuando se mantengan delimitadas por la particularidad de su ser" (Tanabe, 2014: 394-395). Y añade: "La unidad de lo absoluto que resulta de esta transformación práctica de lo específico es lo que puede denominarse lo general. La noción de la especie humana (género) tiene aquí su origen. (...) En tanto que los individuos son los sujetos de esta unidad, pueden alcanzar el amor mutuo y la simpatía que abarca la profundidad de su humanidad, independientemente de si sus países particulares se encuentran en guerra o en paz. En tanto que sus culturas generan e intensifican la peculiaridad de sus 'especificidades', se abren al entendimiento e influencia de una comunidad más penetrante que les permite poseer una validez universal. Al ser mediadas por la libertad y la espontaneidad del individuo, las culturas se comunican entre sí en el nivel profundo de la nada” (Tanabe, 2014: 395). 


\section{Comunidad despierta o sociedad de salvación}

Si nosotros pensásemos qué entiende Tanabe por una sociedad iluminada, diríamos que es aquella en la que en cada uno de sus individuos se diluye la ilusión de la egoidad, para entregarse a la salvación de los otros relativos y hacer de los otros mediadores de la propia liberación. La iluminación no es una libertad personal, sino trabajar en cooperación con otros tras abandonar la ilusión de la egoidad. Para Tanabe esta idea es lograda gracias al espíritu del budismo Mahayana.

No hay manera de escapar del enredo de la egoidad meramente anhelando la huida. El ser relativo solo puede regresar al absoluto a través de una relación que haga de los otros seres relativos sus mediadores; solo a través de la acción de entregarse a los otros seres relativos puede uno liberarse de la egoidad del yo. Si el deseo de una mera liberación an sich necesariamente se convierte en una exigencia de salvación für sich que implica la reconciliación y la cooperación entre el yo y los otros, podemos decir con seguridad que la metanoética es una consecuencia necesaria del espíritu del budismo Mahayana, y por ende, tiene importancia universal. (Tanabe, 2014: 399)

En esta sociedad iluminada los individuos son capaces de "de gozar de un sentido de cooperación armoniosa en la 'equidad ordenada' donde todos trabajen juntos por una instrucción y guía mutuas, de manera que las limitaciones impuestas por la naturaleza no obstruyan nuestra cooperación” (Tanabe, 2014: 399).

Para Tanabe, a pesar de la naturaleza y sus desastres, es necesario que el principio de correlatividad y cooperación (desde la disolución de la egoidad), no se vean destruidos y nos guíen. No es cuidándonos a nosotros mismos como se asegura la existencia, porque la existencia es correlatividad con todo. Dice Tanabe: "Buscar la existencia para uno mismo, destruyendo a todos los otros, es renunciar a la propia existencia. Solo al dar vida a aquellos que existen como otros, al buscar la coexistencia a pesar de la tensión y la oposición y al colaborar por el bien del crecimiento mutuo, el yo encuentra una vida en plenitud" (Tanabe, 2014: 400).

Una sociedad iluminada no es aquella en la que los seres relativos busquen apegarse a la existencia de un yo aislado y a las cosas materiales, por lo cual sometería a los otros, concentrando la riqueza. La sociedad iluminada es aquella en la que el absoluto que es mediación absoluta media a los seres relativos entre sí. Este trabajo de continua mediación mutua produce la transformación continua de los seres relativos. El ser relativo al devenir ser vacío, asegurando la autotrascendencia, abandonándose a sí mismo "se encuentra a sí mismo en cada otro" (Tanabe, 2014: 400). Lo relativo como mediación de la nada absoluta es una existencia que resuci- 
ta en su morir, para convertirse en una existencia sin apegos que se realiza, como ser vacío. Sin embargo, solo cuando la nada es mediación mutua entre los relativos, y cada uno es medio de salvación de los demás, encontramos la nada de transformación: "La nada de la transformación se realiza solo al ser mediada en la sociedad por la dinámica del 'ser vacío'. El mundo de la transformación absoluta, cuyo principio es la nada, no es el mundo de la naturaleza sino el mundo de la historia” (2014).

La sociedad iluminada es aquella que tiene en sí misma el principio de su transformación y renovación, pues los individuos como ejes de la nada que median las transformaciones, giran tanto hacia fuera del ámbito de su sociedad específica como hacia dentro de ella, dando lugar a un no apego. Una sociedad iluminada es una sociedad de equidad basada en la coexistencia, la cooperación y la instrucción mutua. "Dicha sociedad, mientras va pasando por el curso de la historia, se ve renovada continuamente a través de su acción-iluminación. Es un mundo de hermandad fundada en la cooperación humana y la reconciliación. La alegría de construir y habitar este mundo es el significado de la existencia humana" (Tanabe, 2014: 401). Sólo al volverse mediadora de la nada, puede acontecer que la nada sea amor, que el carácter absoluto de la nada haga posible sociedades de hermandad y "la construcción del reino de Dios y el establecimiento del renacimiento en la Tierra” (2014). La nada de transformación no es algo fijo, es acción fe de la nada que actualiza el reino de Dios en la historia en el eterno ahora. No se trata de una meta o de un fin de la historia. La acción fe y la realización del reino de Dios en la Tierra nunca son objeto de contemplación, porque es continua e incesante transformación y acción:

Esta acción-fe-iluminación de la nada, una unidad que nunca puede convertirse en objeto de contemplación, muestra lo que es distintivo de la historia. El no-ser está siempre presente en las profundidades del ser, continuamente transformándolo y convirtiéndolo. El autodespertar de la acción se realiza libremente en un espíritu de desapego e imparcialidad, entrando y saliendo del ser y del no-ser, representa la consumación del reino de Dios en la historia. (Tanabe, 2014: 402)

Sin embargo, esos centros de transformación desde la nada absoluta requieren de zange, y a través de zange, devenir seres vacíos. Solo como seres vacíos, nos transformamos en puntos de giro de la historia, solo al devenir vacíos, de acuerdo al modelo del bodisattva Dharmākara, es posible construir sociedades de hermandad y de correlatividad. Solo por esta vía nos volvemos responsables de las tragedias colectivas, nos volvemos capaces incluso de aminorar los efectos devastadores de huracanes, terremotos e inundaciones. Construir sociedades de hermandad y soli- 
daridad es lo que puede ir permitiendo hacer de este mundo un reflejo de la Tierra Pura. Nishida al final de su última obra escribió: "Este mundo corrupto refleja la Tierra Pura y la Tierra Pura refleja este mundo. Son como dos espejos. Es así, por otra parte, como yo concibo a la nación. La nación no debería ser otra cosa que un reflejo en este mundo de la Tierra Pura" (Kitaro, 2006: 118).

Para Nishida autocontradictoriamente este mundo y la Tierra Pura se determinan mutuamente y permiten determinar este mundo como reflejo de la Tierra Pura. En Tanabe la Tierra Pura determina el lugar, el topos de lo social, permite pensar un mundo del no-ego, donde se realice el ideal del beneficio-propio-qua-beneficiode-otro siguiendo el principio de determinación y afectación de lo específico en un eterno camino de retorno a este mundo siguiendo el camino del bodisattva, pues la figura del bodisattva indica que hasta que el último ser no haya sido liberado, denegamos nuestra entrada al nirvana. El significado de Filosofía como metanoética es el de proponer la transformación del atomismo social del liberalismo, en la transformación de cada uno de nosotros en upāya o medio o en un Entre (Zwischen) o en proponer en lugar de la estatificación del socialismo, impregnado de sustancialización, el retorno al mundo como upayya. Toda la obra de Tanabe es una defensa de la correlatividad, es una defensa de la interrelación, es una defensa de un mundo codependiente, donde el individualismo sólo es una ilusión, pues nuestro verdadero modo de ser es para decirlo nuevamente: upāya. ${ }^{12}$

\section{Más allá de Filosofía como metanoética}

Nobuo Kazashi nos muestra otra dimensión de la colaboratividad y correlatividad en el pensamiento de Tanabe. En el último periodo de su obra, la dimensión relacional se ve ampliada hacia los muertos. Tanabe comprendió esto a la muerte de su esposa Chiyo, en que se descubre en "Zweisamkeit", palabra alemana que da cuenta de un estado en que dos personas se encuentran unidas como en un halo de aislamiento a pesar de la muerte. En ese estado incluso se experimenta la resurrección. Así Kazashi cita lo dicho en una carta por Tanabe a Nogami Yaeko:

12 No hay manera de pensar que la nada que es la que permite la interpenetración y la interrelacionalidad se detenga o que el ser vacío se detenga, él es un eje de transformación. Johannes Laube piensa que el movimiento metanoético queda detenido al final de Filosofía como metanoética al afirmar: "only near the end does he stress the salvific elements. But once he has made the shift, he stops pointing out the duality that characterizes the nature of absolute mediation" (Laube, 1990: 338). 
La muerte de mi esposa ha hecho esto posible, la resurrección es testimoniada, no como un fenómeno natural perteneciente al mundo objetivo, sino como una experiencia espiritual, esto es, como un contenido existencial que aparece en la subjetividad de personalidades unidas por el amor... Para mi sí mismo humilde, también la esposa muerta ha sido resucitada y se encuentra siempre viviendo al interior de mi sí mismo humilde. (Kazashi, 2017: 111-112)

Sin duda alguna estas palabras de Tanabe están dichas desde su ideal bodisattvico de creación de una sociedad supracolaborativa y correlativa. Nobuo Kazashi explica lo dicho por Tanabe: "los muertos son los verdaderos 'otros' en el sentido que nosotros tenemos que vivir y asociarnos con ellos, aún si ellos permanecen incomprensibles para nosotros" (Kazashi, 2017: 112). Este camino de ver la vida desde esta doble dimensionalidad de colaboración no solo entre los vivos, sino también entre los vivos y los muertos, es otra posibilidad de la cooperatividad y colaboratividad, que Tanabe había vislumbrado en Filosofía como metanoética. La colaboratividad no se detiene en los vivos, sino que también es colaboratividad con los muertos. Esto se manifiesta en su texto "¿Una ontología de la vida o una dialéctica de la muerte?” escrito en el homenaje del 70 aniversario del nacimiento de Heidegger:

No hay esperanza de liberación para la especie humana, sin el amor de la colaboración existencial. Con este amor, no puede ser imposible la renovación de la colectividad humana como especie. No podemos buscar la realización de estas esperanzas a través de otro camino sino a través de la muerte y resurrección dialéctica del camino del bodhisattva. Esta es mi convicción (citado por Kazashi, 2017: 113).

Lamentablemente a Nobuo Kazashi le falta comprender que el camino del bodisattva es algo que Tanabe ya había trabajado en Filosofía como metanoética, y que es justamente lo que él trató de esclarecer con su ideal del beneficio propioqua-beneficio de otros, porque en última instancia habría que sostener que de éste depende la renovación de la colectividad humana como especie. De ahí que el bodhisattva no pueda detenerse en el logro del nirvana, en ir a la Tierra Pura, tiene que estar siempre en su viaje de regreso al mundo a colaborar con los otros. ${ }^{13}$

${ }^{13}$ Esta idea la he desarrollado con mayor profundidad en Maldonado Rodriguera (2017). 


\section{Algunas conclusiones}

El vaciamiento del yo (pérdida de centralidad y búsqueda del beneficio propio) tiene como fin una sociedad de correlatividad donde el beneficio propio es qua beneficio de los demás. Ello no debe verse como algo estático, sino como una dinámica. El retorno al mundo acontece cuando se abandona el beneficio propio y se permanece en el mundo en ese trabajo colaborativo, ayudando a otros qua ayudándose a sí mismo de manera continua. En la tradición Mahayana se dice que el bodisattva no abandona este mundo sino hasta que el último ser sintiente sea salvado. Esto es una metáfora del carácter continuo y sin descanso del regreso al mundo. Para Tanabe ese es el principio permanente de creación y renovación social. Por eso la metanoética como el continuo y constante devenir vacío, que no busca salvarse a sí mismo, es también un fundamento de la filosofía de la historia. Desvaneciendo continuamente al sí mismo y continuamente transformándose en ser vacío, se deviene en centro creativo de una sociedad que a su vez, convirtiéndose a su vez vacía, se transforma creativamente trabajando en beneficio de las otras sociedades qua beneficio propio. De ahí el insistente dicho "beneficio propio es qua beneficio de otro" y es el único beneficio propio posible. El continuo vaciamiento es lugar de creación de una interrelación y de una cooperatividad, o "creación de la red de reciprocidad que podemos llamar 'realidad' o 'mundo"' (Laube, 1990: 321). Dar lugar a esta reciprocidad desde el ser vacío como upāya es la aportación de Tanabe a una ontología política. De seguir pensando en centralidades monolíticas y sustanciales, seguiremos errando al buscar el beneficio propio en el olvido del otro. Tanabe busca cambiar esas narrativas sociales, y pensaría, por ejemplo, que el beneficio de los migrantes y de las mujeres es nuestro beneficio propio, el beneficio de plantas y animales es nuestro beneficio propio, porque finalmente, no habría dualidad entre el beneficio propio y el beneficio de otros. Pero también al devenir vacíos sujeto y objeto, no habría un puesto enfrente, sino un entre móvil que se renueva continuamente. 


\section{Bibliografía}

Arnau, Juan. (2006). Antropología del budismo. Barcelona: Kairós.

Bloom, Alfred. (2007). The Essential Shinran: A Buddhist Path of True Entrusting.

Indiana: Bloomington.

Dower, John W. (1999). Embracing Defeat. Japan in the Wake of World War II.

Nueva York: Norton and Company.

Kazashi, Nobuo. (2017). "Metanoetics for the Death and the Living”. En Michiko

Yusa (Comp.), The Bloomsbury Research Handbook of Contemporary Japanese

Philosophy. Londres: Bloomsbury.

Kitaro, Nishida. (2006). Pensar desde la nada (Juan Maisá y Juan Haidar, Trads.).

Salamanca: Ediciones Sígueme.

Laube, Johannes. (1990). "The Way of Metanoia and the Way of Bodisattva”. En

Taitetsu Unno y James W. Heisig (Eds.), The Religious Philosophy of Tanabe Hajime (pp. 316-339). Berkeley: Asian Humanities Press.

Lozoya, Jorge Alberto; y Kerber Palma, Víctor. (2011). “Japón contemporáneo”.

En Michiko Tanaka (Coord.), Historia minima de Japón. México: Colegio de México.

Maldonado Rodriguera, Rebeca. (2017). "A mediação absoluta ou a necessária transformação do ser em um ser Upāya na filosofia como metanoética”. En Antonio Florentino Nieto y Oswaldo Giacoia Jr. (Eds.), A Escola de Kyoto e suas fontes orientais (pp. 149-160). Campinas: Editora Phi.

Ryojın, Soga. (2004). “Bodhisattva Dhārmakara”. En Frederick Frank (Ed.), Buddha Eye: An Anthology of The Kyoto School and Its Contemporaries (pp. 229240). Bloomington: World Wisdom.

TANabe, Hajime. (2014). Filosofía como metanoética (Rebeca Maldonado, Andrés Marquina y Sasha Jair Espinosa, Trads.). México: Herder.

THE LARGER SUTRA. (2003). En The Three Pure Land Sutras (Hisao Inagaki, Trad.). Berkeley: Numata Center for Buddhist Translation and Research. 